\title{
Metabolic Profiling of Glucose-Fed Metabolically Active Resting Zymomonas mobilis Strains
}

\author{
Katsuya Fuchino ${ }^{1}$, Uldis Kalnenieks ${ }^{2}$, Reinis Rutkis ${ }^{2}$, Mara Grube ${ }^{2}$ and Per Bruheim ${ }^{1, *(D)}$ \\ 1 Department of Biotechnology and Food Science, NTNU Norwegian University of Science and Technology, \\ 7491 Trondheim, Norway; Katsuya.Fuchino@ntnu.no \\ 2 Institute of Microbiology and Biotechnology, University of Latvia, LV 1004 Riga, Latvia; \\ uldis.kalnenieks@lu.lv (U.K.); reinis.rutkis@lu.lv (R.R.); mara.grube@lu.lv (M.G.) \\ * Correspondence: Per.Bruheim@ntnu.no
}

Received: 21 January 2020; Accepted: 24 February 2020; Published: 26 February 2020

\begin{abstract}
Zymomonas mobilis is the most efficient bacterial ethanol producer and its physiology is potentially applicable to industrial-scale bioethanol production. However, compared to other industrially important microorganisms, the Z. mobilis metabolome and adaptation to various nutritional and genetic perturbations have been poorly characterized. For rational metabolic engineering, it is essential to understand how central metabolism and intracellular redox balance are maintained in Z. mobilis under various conditions. In this study, we applied quantitative mass spectrometry-based metabolomics to explore how glucose-fed non-growing Z. mobilis Zm6 cells metabolically adapt to change of oxygen availability. Mutants partially impaired in ethanol synthesis $(\mathrm{Zm} 6 \mathrm{adhB})$ or oxidative stress response (Zm6 cat) were also examined. Distinct patterns of adaptation of central metabolite pools due to the change in cultivation condition and between the mutants and $\mathrm{Zm} 6$ reference strain were observed. Decreased NADH/NAD ratio under aerobic incubation corresponded to higher concentrations of the phosphorylated glycolytic intermediates, in accordance with predictions of the kinetic model of Entner-Doudoroff pathway. The effects on the metabolite pools of aerobic to anaerobic transition were similar in the mutants, yet less pronounced. The present data on metabolic plasticity of non-growing Z. mobilis cells will facilitate the further metabolic engineering of the respective strains and their application as biocatalysts.
\end{abstract}

Keywords: Zymomonas mobilis; metabolomics; liquid chromatography-tandem mass spectrometry; Entner-Doudoroff pathway; aerobic respiration; kinetic modelling

\section{Introduction}

Over recent decades, there has been an ever-growing interest in the production of renewable biofuels. Along with yeasts, the alphaproteobacterium Zymomonas mobilis has been attracting significant attention for usage in large-scale biofuels bioprocessing [1]. Z. mobilis possesses several desirable features for biofuels production, such as high specific rate of sugar uptake, presence of active pyruvate carboxylase, tolerance to high concentration of ethanol (11-16\% v/v) and broad range of $\mathrm{pH}(3.5-7.5)$, low biomass production, and relatively small genome size [1-3]. Z. mobilis utilizes Entner-Doudoroff (ED) pathway and can produce ethanol as a final catabolic product at nearly theoretical yield of $0.51 \mathrm{~g}$ $\mathrm{EtOH} / \mathrm{g}$ glucose [3,4]. This bacterium generates only 1 molecule of ATP per catabolizing 1 molecule of glucose, and it has also been shown that its Tricarboxylic acid cycle (TCA) is truncated and Pentose phosphate pathway (PPP) is incomplete [5].

Another distinctive physiological characteristics of Z. mobilis is its high capacity of aerobic respiration, proceeding almost without concomitant energy production [3,6-8]. The primary electron donor in Z. mobilis electron transport chain is NADH $[9,10]$, therefore aerobic respiration results in 
acetaldehyde production by withdrawal of NADH from ethanol synthesis [3,11]. Yet the full scale of physiological consequences of aeration in Z. mobilis remains to be elucidated. For example, it was lately found that anaerobic to aerobic transition significantly influences mevalonate pathway in growing $Z$. mobilis cells [12]. Also, a recent phospho-proteome analysis has revealed that several ED enzymes in $Z$. mobilis cells are phosphorylated during aerobic, but not anaerobic condition [13], pointing to some still unknown modes of regulation within the ED pathway.

Although the high rate of fermentative catabolism and the uncanonical bioenergetics of its aerobic respiration position this bacterium as an efficient producer of catabolic end-products, yet, relative to other industrial workhorses like Escherichia coli and Saccharomyces cerevisiae, the metabolic plasticity of this organism has been poorly characterized. Furthermore, introducing heterologous expression has expanded the potential of Z. mobilis, for example enabling consumption of xylose and other substrates for biofuel production $[14,15]$, but at the same time, metabolic engineering may result in unpredicted alteration of central metabolic fluxes and also influence the intracellular redox balance. It is important therefore to deepen our basic understanding of Z. mobilis central metabolism, redox homeostasis and its relation to the operation of the ED catabolic pathway.

A study by Yang et al. [16] was the first to characterise growing Z. mobilis cells under aerobic and anaerobic situations by metabolomics and transcriptomics. Concerning the intracellular metabolome, these authors focussed on stationary phase cells with near-zero glucose concentration left in their growth media, and used GC-MS metabolite profiling with limited coverage of central metabolite pools. Another recent work [12] monitored the metabolome of exponentially growing cultures during anaerobic to aerobic transition. Kalnenieks et al. [17] reported metabolomes of aerobic batch cultures of several Z. mobilis mutants. These studies revealed dynamic shift of the metabolome and some of its consequences in growing $Z$. mobilis cells.

However, to the best of our knowledge there is no published work on metabolomics of metabolically active non-growing Z. mobilis cells. Resting biocatalyst state with high biomass recycling rates is frequently applied as an industrial bioprocess mode of operation to maximize product yields and minimize carbon loss due to biomass synthesis [18,19]. For a bacterium like Z. mobilis, incorporating less than $5 \%$ of substrate carbon into its biomass [5] and performing catabolism at high rate, metabolism of resting cells represents special biotechnological interest. Exploiting of the resting cell state of Z. mobilis has been attempted since seventies [20], much in the context of immobilized cell preparations [21-23] and thus, profiling the metabolome of resting Z. mobilis cells is of practical importance. Furthermore, application of metabolically active non-growing cells is not restricted to ethanol synthesis, but potentially can serve also for the synthesis of aerobic catabolic products, like acetaldehyde and several other compounds [24].

In the present study, we therefore analysed metabolic profiles of Zymomonas mobilis subsp. ATCC 29191 (Zm6) and its mutant derivatives, catalase and alcohol dehydrogenase knock-out strains with altered aerobic physiology at metabolically active non-growing (resting) state under aerobic and anaerobic condition. Such a comparative metabolomic analysis exposed the scale of catabolic plasticity of Z. mobilis without interfering with pathways related to cellular growth.

\section{Results and Discussion}

\subsection{Shutdown of Cellular Growth Significantly Alters Zymomonas Mobilis Metabolome, Yet Partly Retains Its} High Catabolic Rate

First, a comparison of growing cells and glucose-fed resting cells was performed to investigate how exclusion of cellular growth impacts the central carbon metabolite pools of $\mathrm{Zm6}$. The result from target quantitative mass spectrometry-based metabolite profiling is presented in log2 ratios of resting vs growing $\mathrm{Zm} 6$ cells (Figure 1, left). The analysis revealed quite distinct patterns with larger amino acid and nucleotide pools in growing than in resting cells (Figure 1, left). Glucose consumption rate in aerobically growing Zm6 cells $(30.22 \pm 0.41 \mathrm{mmol} / \mathrm{cell}$ dry weight $\mathrm{g} / \mathrm{h})$ was about 2.5 times higher than in resting cells (Table 1). Notably, this value exceeds almost three times the aerobic glucose 
consumption rate recently reported for aerobically growing E. coli strain, engineered for high glucose throughput [25]. The rate of glucose consumption in non-growing Z. mobilis is thus closely comparable to that seen in growing high glucose throughput strain of E. coli. These results are in agreement with the pattern of 'uncoupled growth', earlier observed in Z. mobilis [7]. The resting state of Z. mobilis cell is metabolically active, which is important for industrially relevant bioprocess setting. In addition, we envision that this system could be exploited for highlighting the metabolic plasticity of Z. mobilis under different conditions.
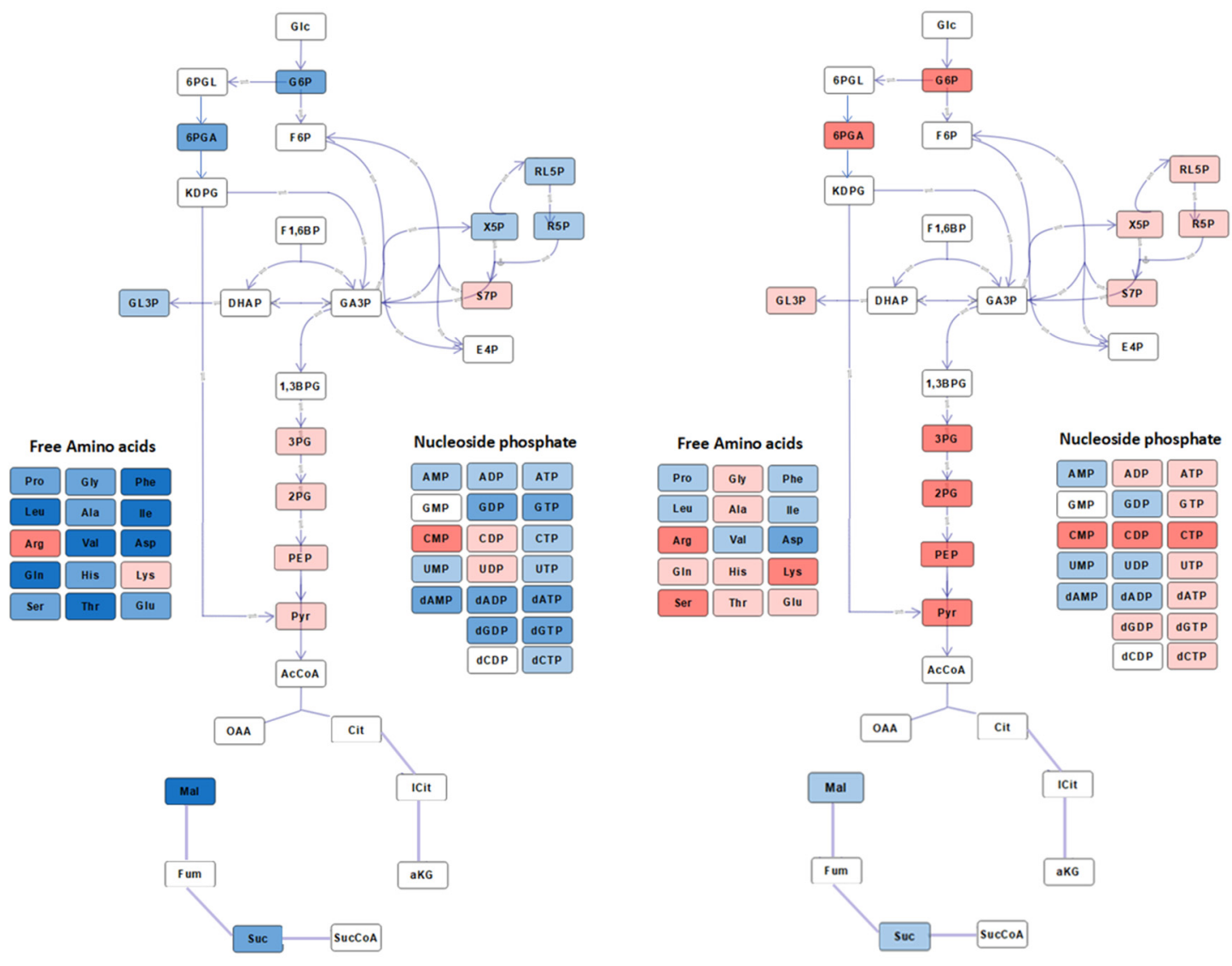

Figure 1. A schematic overview of central carbon metabolism in Z. mobilis, coloured by log2 heatmap of intracellular metabolites concentration in aerobically growing to aerobically resting Zm6 cells (left) and anaerobic to aerobic resting Zm6 cells (right).

Table 1. Steady state glucose consumption rate (glucose $\mathrm{mmol} / \mathrm{cell}$ dry weight $\mathrm{g} / \mathrm{h}$ ) and ethanol yield (g) per glucose $(\mathrm{g})$ during resting cultivations. Each value is a mean of three technical replicates with a standard deviation.

\begin{tabular}{ccccc}
\hline Strain & \multicolumn{2}{c}{ Glucose $\mathbf{m m o l} / \mathbf{C D W} \mathbf{g} / \mathbf{h}$} & \multicolumn{2}{c}{ Y ethanol (g)/glucose $(\mathrm{g})$} \\
\hline & Aerobic & Anaerobic & Aerobic & Anaerobic \\
Zm6 & $12.13 \pm 1.50$ & $20.15 \pm 0.89$ & $0.22 \pm 0.02$ & $0.39 \pm 0.02$ \\
Zm6 cat & $11.27 \pm 0.36$ & $19.45 \pm 0.15$ & $0.18 \pm 0.02$ & $0.32 \pm 0.01$ \\
Zm6 adhB & $12.5 \pm 1.92$ & $15.6 \pm 0.53$ & $0.18 \pm 0.03$ & $0.33 \pm 0.04$ \\
\hline
\end{tabular}

For interpretation of metabolite pool data, it is critical to realize that there is no direct proportionality between pool sizes and fluxes. Quite the opposite can take place in some situations, e.g., in a linear pathway where accumulation of the end-product feedback inhibits the first reaction in the pathway [26]. 
Nevertheless, the increased amino acid and nucleotide pools in growing cells were expected, since in growing cells all biosynthetic pathways were active, while in resting state they were down-regulated. Shutting down the metabolic fluxes to nucleotides and amino acid biosynthesis also led to redistribution among central carbon metabolite pools. The upper ED-pathway metabolites G6P and 6PGA were down-regulated while the lower ED pathway metabolites PEP, 3PG-2PG and Pyr were significantly increased in resting cells (Figure 1, left). This was not due to altered redox-balance, since NADH/NAD ratio did not dramatically change after stopping growth (Table 2), nor was the adenylate energy charge significantly different in each case (Table S1).

Table 2. NADH/NAD ratio in each $Z$. mobilis strain at steady state during resting cultivation. $\mathrm{NADH} / \mathrm{NAD}$ ratio is an average of 4 technical replicates. $\mathrm{RSD}=$ relative standard deviation.

\begin{tabular}{cccc}
\hline \multicolumn{2}{c}{ Strains and Conditions } & NADH/NAD & RSD (\%) \\
\hline \multirow{2}{*}{ Zm6 resting } & Aerobic & 0.51 & 38.11 \\
& Anaerobic & 0.99 & 30.38 \\
Zm6 cat resting & Aerobic & 0.57 & 15.1 \\
& Anaerobic & 0.46 & 20.8 \\
Zm6 adhB resting & Aerobic & 0.61 & 16.35 \\
Zm6 growing & Anaerobic & 0.74 & 1.97 \\
& Aerobic & 0.58 & 4.8 \\
\hline
\end{tabular}

2.2. Aerobic to Anaerobic Transition Upregulates NADH/NAD, yet Downregulates ED Pathway Metabolite Pools

Next, we compared metabolite pool profiles of non-growing, steady-state Zm6 cells under aerobic and anaerobic condition. The resting cell cultures were first incubated under aerobic condition, and then switched to anaerobic condition by flushing nitrogen gas instead of air. Samples were taken after a steady rate of glucose consumption had been established both under aerobic and anaerobic condition, avoiding sampling during the transition state (see Methods). Interestingly, all ED pathway metabolite pools were downregulated under anaerobic condition (Figure 1, right), although the specific glucose consumption rate almost doubled after switching to nitrogen gassing (Table 1).

To see if this could be anticipated from the known kinetic parameters of the ED pathway, we ran simulations of the aerobic to anaerobic transition (Figure 2) using the ED pathway kinetic model for non-growing Z. mobilis [8,27]. Our simulations supported higher metabolite pools (compare the data on glucose-6-phosphate, 6-phosphogluconate and the ED intermediates downstream glyceraldehyde-3-phosphate; Figure 2) and lower NADH/NAD ratio under aerobic incubation, like found in the present experiments. Elevation of pools downstream glyceraldehyde-3-phosphate during the anaerobic to aerobic transition is supported also by data of Martien et al. [12] on growing cells. Besides, the model suggests that lowering of NADH/NAD ratio should lead to higher rate of glycolysis via the Z. mobilis ED pathway, apparently because faster glycolysis requires more NAD for metabolizing sugar [28], and that the glyceraldehyde-3-phosphate dehydrogenase (GAPDH) might be the reaction, initially responding to the drop of NADH/NAD. Interestingly, apart from stimulation of the glycolytic rate, several recent studies indicate that low NADH/NAD is particularly beneficial under various stress conditions, including saline and acetic acid stress [28-31]. 


\begin{tabular}{|l|c|c|c|c|}
\cline { 2 - 5 } \multicolumn{1}{c|}{} & \multicolumn{2}{c|}{ Simulation } & Experiental \\
\hline Metabolites & $\begin{array}{c}\text { Anaerobic } \\
\mu \mathrm{M}\end{array}$ & $\begin{array}{c}\text { Aerobic ** } \\
\mu \mathrm{M}\end{array}$ & $\begin{array}{c}\text { Anaerobic/ } \\
\text { Aerobic } \\
\text { log2 ratio }\end{array}$ & $\begin{array}{c}\text { Anaerobic/ } \\
\text { Aerobic } \\
\log 2 \text { ratio }\end{array}$ \\
\hline Glucose 6-phosphate & 1815 & 12,383 & -2.77 & -2.06 \\
6-Phosphogluconic acid & 268 & 824 & -1.62 & -1.85 \\
6-phosphogluconolactone & 239 & 3290 & -3.78 & NA \\
2-Keto-3-deoxy-6-phosphogluconate & 920 & 679 & 0.44 & NA \\
Glycealdehyde 3-phosphate & 354 & 134 & 1.40 & NA \\
1, 3-bisphosphoglycerate & 4 & 42 & -3.39 & NA \\
3-phosphoglycerate *** & 2774 & 7954 & -1.52 & $-1.95 * * *$ \\
2-phosphoglycerate *** & 230 & 638 & -1.47 & -2.63 \\
Phosphoenolpyruvate & 66 & 241 & -1.87 & -1.16 \\
Pyruvate & 935 & 1396 & -0.58 & NA \\
Acetaldehyde & 48 & 14,369 & -8.23 & NA \\
NAD & 1518 & 4497 & -1.57 & NA \\
NADH & 2982 & 3 & 9.96 & 0.01 \\
ATP* & 1671 & 2928 & -0.81 & -0.31 \\
ADP* & 1313 & 524 & 1.33 & -0.73 \\
AMP* & 516 & 47 & 3.46 & 3 \\
* Model simulation as described in Rutkis et al. 2013. & -3 & & 0 \\
** Model simulation as described in Rutkis et al. 2016. & & & \\
*** The log2 ratio of combined concentration of 2-phophoglycerate and 3-phosphoglycerate. & \\
\hline
\end{tabular}

Figure 2. In silico simulation of ED intermediate pools in resting Z. mobilis cells and comparison to the experimental data. The simulation was conducted employing ED pathway kinetic model in non-growing Z. mobilis as described in $[8,27]$.

Under anaerobic conditions, the observed specific rate of glucose consumption in Zm6 was around $20 \mathrm{mmoles} / \mathrm{g}$ dry weight $\mathrm{hr}$, reasonably close to the model-generated value of $27 \mathrm{mmoles} / \mathrm{g}$ dry weight hr [8]. However, in accordance with the lowered NADH/NAD ratio (but in contrast to the present experimental results), the model predicted higher glucose uptake rate under aerobic conditions. We speculate that such a discrepancy between the model simulations and the present experiments could at least in part be caused by the inhibitory effect of acetaldehyde. The model does not take into account possible inhibitory action of the accumulated acetaldehyde, therefore, the simulation results have been previously verified experimentally, using vigorous gassing of air ( $2.5 \mathrm{v} / \mathrm{v}$ per $\mathrm{min})$ through the culture to remove most of acetaldehyde [8]. Under such vigorous gassing, an aerobic increase of glycolytic rate actually did take place. In the present work at $0.8 \mathrm{v} / \mathrm{v}$ per min aeration acetaldehyde was not thoroughly gassed out (like in most of aerobic growth experiments with Z. mobilis), so its inhibitory effect could largely contribute to the slowdown of aerobic glycolysis. At the end of aerobic incubation its concentration in cell suspensions of $\mathrm{Zm} 6$ and $\mathrm{Zm} 6$ adhB had reached $0.3 \mathrm{~g} \mathrm{~L}^{-1}$, while in $\mathrm{Zm} 6$ cat it was close to $0.4 \mathrm{~g} \mathrm{~L}^{-1}$ (not shown), which was in the range of acetaldehyde concentrations showing a distinct inhibitory effect [11]. Remarkably however, in both experimental setups and in model simulation the aerobic pools of ED metabolites were higher than the anaerobic ones, independently of the difference of glucose consumption rates in each case. From this we conclude that there is no relation between the net glycolytic flux rate and the concentration of phosphorylated intermediates in Z. mobilis during the aerobic to anaerobic transition.

As expected, the ethanol yield upon transition to anaerobic condition also increased, from 0.22 to 0.39 (ethanol (g)/glucose (g)). Apparently, the absence of oxygen as the terminal electron acceptor 
directed more reducing equivalents to reduction of acetaldehyde by alcohol dehydronase. However, Zm6 cells still maintained a significantly higher NADH/NAD ratio under anaerobic conditions (Table 2). Only minor adjustments were observed among amino acids and nucleotides during the shift. Even though ATP was slightly downregulated, the anaerobic Zm6 cells kept almost the same energy charge as that of aerobic cells (Table S1). That is not surprising since the main ATP generating mechanism in both aerobic and anaerobic Zm6 cells is substrate-level phosphorylation [3].

\subsection{Metabolite Profiling of Mutants With Partially Impaired Ethanol Synthesis (Zm6 adhB) or Enhanced Respiratory Capacity (Zm6 cat) Exhibit Common Trends}

Next, we performed the same metabolite profiling approach on resting Zm6 cat and Zm6 adhB mutants. The Zm6 cat mutant was included in this study due to its interesting phenotype, an elevated aerobic respiration capacity [32], and accordingly, an improved capacity of acetaldehyde synthesis [31]. This strain was shown to be sensitive to hydrogen peroxide due to the lack of catalase activity [32], but the mutation did not cause growth deficiency under aerobic condition, suggesting that the mutant was still able to cope with general oxidative stress [17]. The mechanism by which the mutant upregulates oxygen consumption is not understood, but it is likely that its redox dynamics is altered. In Z. mobilis, there are two alcohol dehydrogenase enzymes (AdhI encoded by adhA and AdhII encoded by $a d h B$ ). The Zm6 adhB strain was chosen for metabolomic study because of its altered redox dynamics [33,34], and also its potential use for industrial acetaldehyde production due to lower ethanol-synthesising activity [17].

The effect of aeration upon the cellular content of protein, nucleic acids, carbohydrates and lipids (in percent of cell dry weight) in all three strains was estimated from the Fourier-transform infrared spectra (FTIR) of the biomass samples. This study was undertaken as a complimentary investigation to assess if major changes in biomass composition in mutant strains could be direct explanations to potential differences in metabolite profiles. FTIR is a rapid method, particularly suited for monitoring the relative change of the cellular content of each macromolecular component under varying conditions [35]. In the present study the infrared spectra revealed a pattern of macromolecular composition of stationary phase cells, which was largely similar to previously reported data, obtained by alternative methods [36,37]. Protein varied in the range between 59 and $64 \%$ of cell dry weight, while nucleic acids constituted 14.5-17\% (not shown). Both these components showed no significant variability between the strains or aeration conditions. However, in all three strains the lipid content was lower under aerobic condition; a characteristics indicative for oxidative stress condition [38]. In addition, in Zm6 cat strain aerobically cultivated cells showed an increase in carbohydrate content (Figure 3).

The glucose consumption rate during both aerobic and anaerobic resting state was similar to $\mathrm{Zm} 6$ reference in the $\mathrm{Zm} 6$ cat mutant (Table 1). The ethanol yields in Zm6 cat were lower, especially under aerobic conditions, supporting the phenotype of Zm6 cat mutant with higher respiratory rate and accumulation of acetaldehyde [17]. Interestingly, the NADH/ NAD ratio was similar to that of $\mathrm{Zm} 6$ under aerobic conditions, whereas its increase was not observed in Zm6 cat under transition to anaerobic conditions; rather a slight decrease took place (Table 2). In general, deletion of cat locus had a high impact on the central carbon metabolism under aerobic condition (Table 3a, see the left column, Zm6 cat/Zm6), causing aerobic downregulation of most ED-pathway intermediate metabolites. This observation further supports the absence of correlation between the net glycolytic flux rate and the concentration of phosphorylated intermediates, since the ED pathway flux in Zm6 cat strain is very similar to that in $\mathrm{Zm} 6$. 


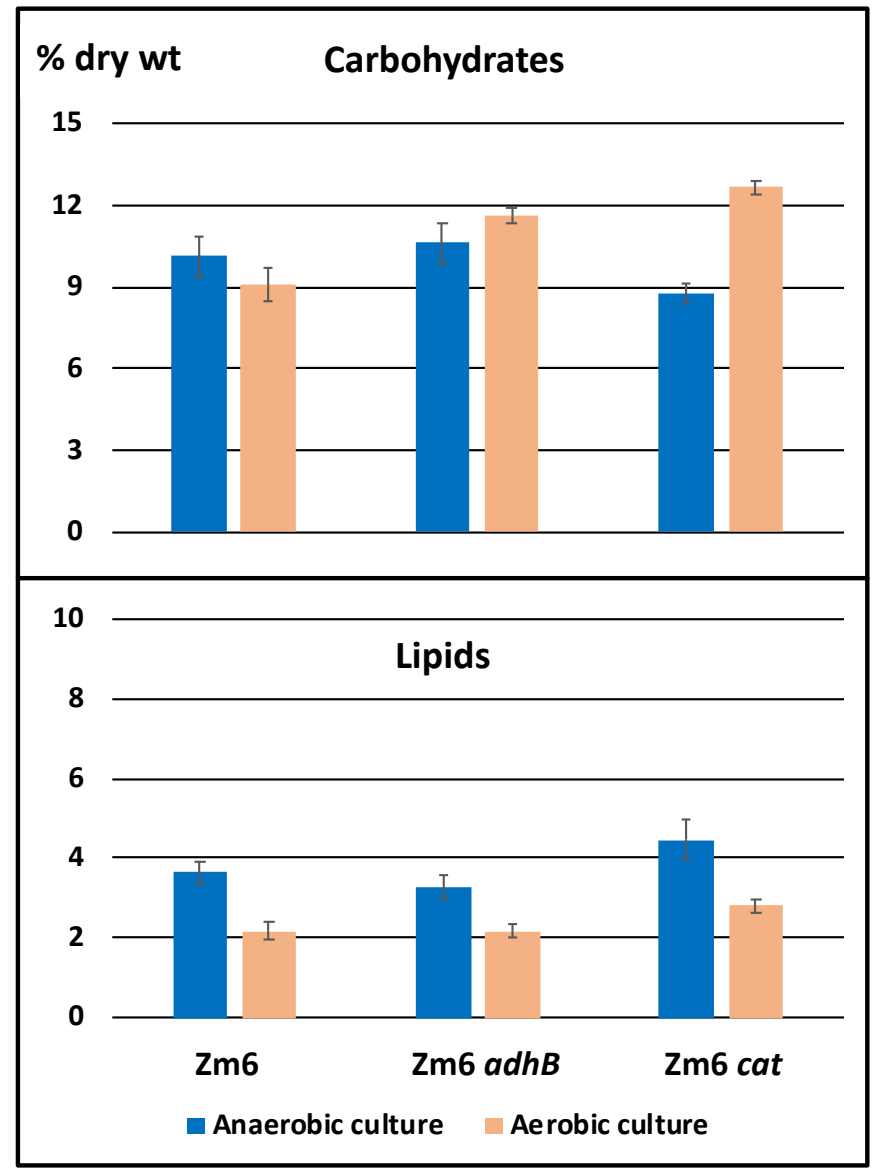

Figure 3. Total carbohydrate and lipid content (\% of dry weight) in the stationary phase cells of Zm6, $\mathrm{Zm} 6 \mathrm{adhB}$ and Zm6 cat strains, grown under anaerobic or aerobic conditions.

The Zm6 adhB strain exhibited similar glucose consumption rates to Zm6 in aerobic condition, but significantly lower under anaerobic situation (Table 1). The ethanol yield was lower in both conditions, probably due to accumulation of acetaldehyde. Ethanol in the $\mathrm{Zm} 6$ adhB mutant is produced only by AdhI and that enables maintenance of the glucose uptake and intracellular conversion to ethanol at about $75 \%$ of the wild type reference. Introduction of a flux limitation at the last step of ethanol biosynthesis pathway had consequences for the upstream metabolite pools. In the aerobic situation several ED pathway metabolites were down-regulated, while most of them being upregulated in the anaerobic situation, relative to the $\mathrm{Zm} 6$ reference (Table $3 b$, see the left column). The NADH/NAD ratio in the $\mathrm{Zm} 6$ adhB mutant tended to increase under anaerobic condition, exhibiting the same pattern as in Zm6, yet the change was much smaller. The dynamics of the ED intermediates around the pyruvate node differed most between $\mathrm{Zm} 6 \mathrm{adhB}$ and $\mathrm{Zm} 6$.

Taken together, we found that relative to Zm6, deletion of cat and $a d h B$ locus elicited similar global trends in the central carbon metabolites, both under aerobic and anaerobic conditions (compare the left and middle columns in Table $3 a$ and $b$ ). These two mutations both led to narrower intervals of change of NADH/NAD ratio and of phosphorylated intermediate concentrations, than seen in the parental strain upon the aerobic to anaerobic transition. In all cases, the lower NADH/ NAD ratio corresponded to higher concentrations of the phosphorylated glycolytic intermediates, in accordance with the model predictions [8]. Furthermore, the magnitude of the NADH/NAD ratio is expected to influence acetaldehyde production, although via different mechanisms (increase of respiratory activity in cat vs. decrease of alcohol dehydrogenase activity in $\mathrm{Zm} 6$ adhB). Apparently, the aerobic overproduction of the inhibitory metabolite acetaldehyde in both these strains (in addition to the effect 
of NADH/NAD ratio per se) largely determined the observed metabolite pool balance around the pyruvate node and also upstream the ED pathway.

Table 3. $\mathbf{a}$ (left) and $\mathbf{b}$ (right). $\log 2$ heatmap of metabolites concentration in each resting strain versus resting $\mathrm{Zm} 6$ under aerobic (left column), anaerobic (middle column), and anaerobic vs aerobic in each resting strain (right column). Abbreviation of metabolites are as in Table S2. Colour gradient; scale of $\log 2$ value.

\begin{tabular}{|c|c|c|c|c|c|c|c|}
\hline & $\begin{array}{c}\mathrm{Zm6} \text { cat } / \\
\mathrm{Zm} 6\end{array}$ & $\begin{array}{c}\mathrm{Zm6} \text { cat } / \\
\mathrm{Zm} 6\end{array}$ & $\mathrm{Zm} 6$ cat & & $\begin{array}{c}\mathrm{Zm6} \text { adh/ } \\
\mathrm{Zm} 6\end{array}$ & $\begin{array}{c}\mathrm{Zm} 6 \text { adh/ } \\
\mathrm{Zm} 6\end{array}$ & $\mathrm{Zm} 6$ adh \\
\hline & Aerobic & Anaerobic & $\begin{array}{l}\text { Anaerobic } \\
\text { /Aerobic }\end{array}$ & & Aerobic & Anaerobic & $\begin{array}{c}\text { Anaerobic } \\
\text { /Aerobic }\end{array}$ \\
\hline G6P & -2.16 & 0.69 & 0.79 & G6P & -1.01 & 0.73 & -0.32 \\
\hline 6PGA & 1.20 & 2.77 & -0.28 & 6PGA & 1.17 & 2.23 & -0.79 \\
\hline P5P & 1.57 & 1.91 & 0.25 & P5P & 0.94 & 1.98 & 0.94 \\
\hline Sedo-7p & 2.05 & 0.81 & -1.49 & Sedo-7p & 0.59 & 0.05 & -0.78 \\
\hline Gly-3p & 0.98 & 1.85 & 0.52 & Gly-3p & 0.68 & 1.96 & 0.94 \\
\hline 3PG-2PG & -1.04 & 0.88 & -0.04 & 3PG-2PG & -1.62 & 0.91 & 0.58 \\
\hline PEP & -1.98 & 0.22 & -0.43 & PEP & -2.08 & 0.60 & 0.05 \\
\hline Pyr & -2.20 & -0.80 & 0.24 & Pyr & -1.80 & -0.40 & 0.24 \\
\hline Suc & 0.27 & 1.52 & 1.38 & Suc & 0.60 & 0.66 & 0.18 \\
\hline Mal & 0.93 & 2.07 & 1.42 & Mal & -1.12 & -0.13 & 1.26 \\
\hline AMP & 0.65 & -0.09 & -0.73 & AMP & 0.13 & -0.60 & -0.72 \\
\hline ADP & 0.40 & 0.29 & -0.42 & $\mathrm{ADP}$ & 0.17 & 0.02 & -0.46 \\
\hline ATP & 0.04 & 0.53 & -0.24 & ATP & 0.55 & 0.70 & -0.59 \\
\hline GDP & 0.45 & 0.29 & 0.11 & GDP & 0.21 & -0.01 & 0.05 \\
\hline GTP & 0.21 & 0.53 & 0.20 & GTP & 0.24 & 0.43 & 0.06 \\
\hline CMP & -0.18 & 1.63 & 0.19 & CMP & -0.24 & -0.28 & -1.66 \\
\hline $\mathrm{CDP}$ & 0.20 & 0.57 & -0.63 & $\mathrm{CDP}$ & -0.44 & -0.59 & -1.16 \\
\hline СТP & 0.68 & 1.12 & -0.71 & СТP & 0.63 & 0.88 & -0.91 \\
\hline UMP & 0.09 & 0.41 & 0.53 & UMP & 0.05 & -0.22 & -0.06 \\
\hline UDP & 0.21 & 0.12 & 0.05 & UDP & -0.08 & -0.47 & -0.25 \\
\hline UTP & 0.47 & 0.54 & -0.12 & UTP & 0.34 & 0.41 & -0.12 \\
\hline dAMP & 0.85 & 0.56 & 0.05 & dAMP & -0.91 & -1.08 & 0.17 \\
\hline dADP & 0.63 & 1.27 & 0.82 & dADP & -1.18 & -1.28 & 0.08 \\
\hline dATP & -0.11 & 1.37 & 1.22 & dATP & -0.92 & -0.68 & -0.02 \\
\hline dGDP & -0.09 & -1.86 & -2.01 & dGDP & 0.99 & -0.49 & -1.72 \\
\hline dGTP & -0.15 & 1.50 & 0.74 & dGTP & 0.30 & -0.53 & -1.74 \\
\hline dUMP & 1.22 & 0.00 & -0.81 & dUMP & 1.22 & 0.32 & -0.49 \\
\hline dUTP & 0.83 & 0.19 & 0.00 & dUTP & 1.22 & 0.10 & -0.49 \\
\hline dCTP & 0.33 & 0.66 & -0.45 & $\mathrm{dCTP}$ & 0.40 & 0.08 & -1.10 \\
\hline Gly & -0.12 & 0.76 & 0.80 & Gly & -0.66 & -0.48 & 0.12 \\
\hline Ala & 0.52 & 0.35 & -0.22 & Ala & 0.88 & -0.09 & -1.01 \\
\hline Ser & 0.25 & 0.76 & -0.65 & Ser & 0.00 & 0.69 & -0.47 \\
\hline Pro & 0.57 & 1.21 & 0.68 & Pro & 1.66 & 1.25 & -0.37 \\
\hline Val & 0.12 & 0.27 & 0.70 & Val & 0.27 & -0.22 & 0.06 \\
\hline Thr & 0.49 & 0.58 & 0.00 & Thr & 0.34 & 0.23 & -0.21 \\
\hline Ile & 0.00 & 0.02 & 0.55 & Ile & 0.38 & -0.05 & 0.11 \\
\hline Leu & -0.04 & 0.10 & 0.85 & Leu & 0.38 & -0.03 & 0.31 \\
\hline Asp & 1.14 & 0.83 & 0.86 & Asp & 1.92 & 0.95 & 0.19 \\
\hline Gln & 1.65 & 2.12 & -0.29 & Gln & 1.22 & 0.94 & -1.03 \\
\hline Glu & 0.26 & 0.71 & -0.13 & Glu & -0.11 & -0.12 & -0.58 \\
\hline His & 0.17 & 0.32 & 0.07 & His & -0.20 & 0.15 & 0.26 \\
\hline Phe & -1.11 & -0.82 & 0.74 & Phe & -1.25 & -1.67 & 0.03 \\
\hline Arg & -0.43 & 0.71 & -0.68 & Arg & -1.11 & -0.04 & -0.76 \\
\hline Lys & -0.41 & 0.55 & -0.38 & Lys & -1.36 & -0.59 & -0.56 \\
\hline
\end{tabular}

In conclusion, our results exemplify that the control of central metabolic fluxes is a complex phenomenon and predicting all consequences of the strain metabolic engineering at sufficient precision 
is still challenging. This unpredictability is particularly pronounced when toxic volatile compounds are produced and excreted in the medium during cultivation, like acetaldehyde in the case of $Z$. mobilis. Nevertheless, here at a semi-quantitative level the predictions of the kinetic model of the Entner-Doudoroff pathway proved to comply with the observed metabolome dynamics during transition between different modes of aeration, at least correctly simulating the directionality of change of metabolite concentrations. Acquiring more reference metabolome data on Z. mobilis catabolism is mandatory for improvement of the present E-D pathway kinetic model, especially with regards to simulations of Zymomonas aerobic catabolism. An improved kinetic model would allow more rigorous quantitative analysis of the flux, including metabolic control analysis (MCA) for highlighting the metabolic bottlenecks as the potential targets of genetic engineering. This type of interaction between metabolomics and model building would result in a better kinetic model. That in its turn would enable design of novel, perhaps counterintuitive, metabolic engineering strategies for Z. mobilis central metabolism, including those, directed towards use of respiratory mutants as biocatalysts for broadening of the aerobic product spectrum.

\section{Materials and Methods}

Z. mobilis ATCC 29191 (Zm6) was cultivated in 3 litre fermentors (Eppendorf New Brunswick 115 series bioreactor) with 1.2 litre operating volume. Cells were grown at $30^{\circ} \mathrm{C}$ in a complex growth medium containing glucose $(20 \mathrm{~g} / \mathrm{L})$, yeast extract $(5 \mathrm{~g} / \mathrm{L}), \mathrm{NH}_{4} \mathrm{SO}_{4}(1 \mathrm{~g} / \mathrm{L}), \mathrm{KH}_{2} \mathrm{PO}_{4}(1 \mathrm{~g} / \mathrm{L}), \mathrm{MgSO}_{4}$ $(0.5 \mathrm{~g} / \mathrm{L})$, as described previously [39]. The $\mathrm{pH}$ in the medium was adjusted to $5.5 \mathrm{by} \mathrm{NaOH}$ during all fermentation. Atmospheric air flow was set at $1.0 \mathrm{~L} / \mathrm{min}$, and off-gas from fermenters was monitored by DASGIP ${ }^{\circledR}$ gas analyser (Eppendorf Bioprocess Center Europe, Jülich, Germany). Cultivation for resting cells was performed as follows. Cells were grown under fully controlled aerobic condition. The fully-grown cells that reached stationary phase were collected by centrifuge (10 min, $5000 \mathrm{rpm}$ ), washed twice in salt solution containing $\mathrm{KH}_{2} \mathrm{PO}_{4}(1 \mathrm{~g} / \mathrm{L})$ and $\mathrm{MgSO}_{4}(0.5 \mathrm{~g} / \mathrm{L})$, resuspended in the salt solution supplemented with $10 \mathrm{~g} / \mathrm{L}$ glucose. The resting culture were incubated aerobically for $2.5 \mathrm{~h}$. After that, anaerobic incubation was started by gassing with nitrogen at $1.0 \mathrm{~L} / \mathrm{min}$. Parental strain $\mathrm{Zm} 6$, the Zm6 cat [32], and the Zm6 adhB mutant lacking alcohol dehydrogenese [33] were chosen for resting cell experiments.

Sampling was performed at 75th and 120th minute after aerobic resting cultivation had started, and at 45th and 90th minute after switching to anaerobic condition. These sampling time points corresponded to catabolic steady state, as judged from glucose consumption rate. Quenching of samples were performed as previously described [40]. Cells were filtered through Polyethersulfone membrane disc filters (Pall), washed by cold salt solution $\left(\mathrm{MgSO}_{4} 0.5 \mathrm{~g} / \mathrm{L}\right.$ and $\mathrm{KH}_{2} \mathrm{PO}_{4} 1 \mathrm{~g} / \mathrm{L}$ ) and cold milli-Q water. Filtered samples were then quenched by $\mathrm{ACN}$ and $\mathrm{H}_{2} \mathrm{O}$ mixture (55\% and $45 \%$ ), and snap-freezed by liquid nitrogen. Collected cells were disrupted by 3 cycles of freezing and thawing, and lyophilized for storage at $-80^{\circ} \mathrm{C}$. Prior to the analysis, the freeze-dried samples were resuspended in MS grade $\mathrm{H}_{2} \mathrm{O}$ (VWR) and spin-filtered with low protein binding filter (VWR).

The measurement of phosphorylated sugars and nucleotides were performed using capillary ion chromatography $[40,41]$ coupled to tandem mass spectrometry Xevo TQ-XS Triple Quadrupole Mass Spectrometry (Waters, Milford, MA, USA). Free amino acids and Organic acids were derivatized by Edman's reagent [42] and O-Benzylhydroxylamine [43], respectively. Derivatized samples were analysed by ACQUITY I-Class UPLC (Waters) coupled to TQ-XS. Software MassLynx (Waters) was used for data acquisition, and its application TargetLynx (Waters) was used for processing the data. Metabolite concentrations were average of two time points for each condition and normalized according to dry weight and optical density at $600 \mathrm{~nm}(\mathrm{OD})$ for a comparative analysis.

The kinetic model of Z. mobilis E-D pathway used in this study has been described and validated previously [8,27]. Kinetic modeling was carried out using COPASI software. The model simulations in the present work were intended to reproduce the directionality of the observed effects, without attempts to obtain quantitative precision. 
For FTIR spectroscopy, bacterial biomass was washed with distilled water in triple to remove the growth medium. FTIR spectra of bacterial biomass were recorded using a high throughput screening extension (HTS-XT) coupled to a Vertex 70 spectrometer (Bruker Optik GmbH, Ettlingen, Germany) equipped with a globular mid-IR source and a DTGS detector. 5-10 $\mu \mathrm{L}$ aliquots of bacterial cell suspension in water were pipetted on a 384 well silicon microplate in three replicates and dried at $\mathrm{T}<50{ }^{\circ} \mathrm{C}$. Absorption spectra were collected over the wavenumber range of $4000-600 \mathrm{~cm}^{-1} \mathrm{with}^{-}$ a resolution of $4 \mathrm{~cm}^{-1}, 64$ scans. Baseline was corrected using the rubber band method, and $\mathrm{CO}_{2}$ bands were excluded. For data analyses spectra in the absorption range of $0.25-0.80$ were used (the range in which the concentration of a component is proportional to the intensity of its absorption band, according to the Lambert-Bouger-Beer law). Data were processed using OPUS 6.5 software. The content of carbohydrates, nucleic acids, proteins and lipids in biomass was calculated as in Grube et al. [35].

Glucose and ethanol concentrations in the spent media during resting incubation was measured using Waters 2695e Alliance HPLC (Waters). Hi-plex column $(300 \times 7.7 \mathrm{~mm}$, Agilent, Santa Clara, CA, USA) was used at column temperature $45^{\circ} \mathrm{C}$, with $0.05 \mathrm{M}$ sulfuric acid as mobile phase at a flow rate of $0.8 \mathrm{~mL} / \mathrm{min}$. The concentration in samples was calculated from a linear external standard curve. Acetaldehyde concentration was monitored enzymatically using 'Megazyme' analytical kit, following manufacturer's instructions.

$\mathrm{NADH} / \mathrm{NAD}$ measurement by an enzymatic assay was performed according to the instruction supplied by the manufacturer (Sigma, Saint Louis, MI, USA). Cells were collected and spin down by centrifuge at the time of samplings. Pelleted cells were then snap-frozen by liquid nitrogen and stored at $-80{ }^{\circ} \mathrm{C}$ until the samples were used for measurements. Upon the analysis, cells were thawed on ice and resuspended in the buffer supplied from the kit. Absorbance at $450 \mathrm{~nm}$ was measured every 15 min using 96 well-plates in plate-reader spark 20M (Tecan, Männedorf, Switzerland).

Supplementary Materials: The following are available online at http://www.mdpi.com/2218-1989/10/3/81/s1, Table S1: A table of concentrations of metabolites analysed in this study, Table S2: List of abbreviation of metabolites.

Author Contributions: Conceptualization, K.F. and P.B.; methodology, K.F., U.K. and P.B.; validation, K.F., U.K. and P.B.; formal analysis, K.F., U.K., R.R., M.G. and P.B.; investigation, K.F., U.K., R.R., M.G. and P.B.; data curation, K.F., U.K. and P.B.; writing-review and editing, K.F., U.K. and P.B. All authors have read and agreed to the published version of the manuscript.

Funding: This research was funded by The Research Council of Norway, grant number 258657, and by the Latvian ERDF project 1.1.1.1/16/A/185 and Latvian Council of Science project lzp-2018/2-0123.

Acknowledgments: The authors are grateful to Kåre Andre Kristiansen for a technical assistance.

Conflicts of Interest: The authors declare no conflict of interest.

\section{References}

1. Yang, S.; Fei, Q.; Zhang, Y.; Contreras, L.M.; Utturkar, S.M.; Brown, S.D.; Himmel, M.E.; Zhang, M. Zymomonas mobilis as a model system for production of biofuels and biochemicals. Microb. Biotechnol. 2016, 9, 699-717. [CrossRef] [PubMed]

2. Seo, J.-S.; Chong, H.; Park, H.S.; Yoon, K.-O.; Jung, C.; Kim, J.J.; Hong, J.H.; Kim, H.; Kim, J.-H.; Kil, J.-I.; et al. The genome sequence of the ethanologenic bacterium Zymomonas mobilis ZM4. Nat. Biotechnol. 2005, 23, 63-68. [CrossRef] [PubMed]

3. Kalnenieks, U. Physiology of Zymomonas mobilis: Some Unanswered Questions. In Advances in Microbial Physiology; Poole, R.K., Ed.; Academic Press: Cambridge, MA, USA, 2006; Volume 51, pp. 73-117.

4. Rogers, P.L.; Jeon, Y.J.; Lee, K.J.; Lawford, H.G. Zymomonas mobilis for Fuel Ethanol and HigherValue Products. In Biofuels; Olsson, L., Ed.; Springer: Berlin/Heidelberg, Germany, 2007; pp. 263-288.

5. De Graaf, A.A.; Striegel, K.; Wittig, R.M.; Laufer, B.; Schmitz, G.; Wiechert, W.; Sprenger, G.A.; Sahm, H. Metabolic state of Zymomonas mobilis in glucose-, fructose-, and xylose-fed continuous cultures as analysed by 13 C- and 31 P-NMR spectroscopy. Arch. Microbiol. 1999, 171, 371-385. [CrossRef] [PubMed] 
6. Rutkis, R.; Galinina, N.; Strazdina, I.; Kalnenieks, U. The inefficient aerobic energetics of Zymomonas mobilis: Identifying the bottleneck. J. Basic Microbiol. 2014, 54, 1090-1097. [CrossRef] [PubMed]

7. Belaïch, J.-P.; Senez, J.C. Influence of Aeration and of Pantothenate on Growth Yields of Zymomonas mobilis. J. Bacteriol. 1965, 89, 1195. [CrossRef]

8. Rutkis, R.; Strazdina, I.; Balodite, E.; Lasa, Z.; Galinina, N.; Kalnenieks, U. The Low Energy-Coupling Respiration in Zymomonas mobilis Accelerates Flux in the Entner-Doudoroff Pathway. PLoS ONE 2016, 11, e0153866. [CrossRef]

9. Kalnenieks, U.; Galinina, N.; Strazdina, I.; Kravale, Z.; Pickford, J.L.; Rutkis, R.; Poole, R.K. NADH dehydrogenase deficiency results in low respiration rate and improved aerobic growth of Zymomonas mobilis. Microbiology 2008, 154, 989-994. [CrossRef]

10. Strazdina, I.; Balodite, E.; Lasa, Z.; Rutkis, R.; Galinina, N.; Kalnenieks, U. Aerobic catabolism and respiratory lactate bypass in Ndh-negative Zymomonas mobilis. Metab. Eng. Commun. 2018, 7, e00081. [CrossRef]

11. Ishikawa, H.; Nobayashi, H.; Tanaka, H. Mechanism of fermentation performance of Zymomonas mobilis under oxygen supply in batch culture. J. Ferment. Bioeng. 1990, 70, 34-40. [CrossRef]

12. Martien, J.I.; Hebert, A.S.; Stevenson, D.M.; Regner, M.R.; Khana, D.B.; Coon, J.J.; Amador-Noguez, D. Systems-Level Analysis of Oxygen Exposure in Zymomonas mobilis; Implications for Isoprenoid Production. mSystems 2019, 4, e00284-18. [CrossRef]

13. Tatli, M.; Hebert, A.S.; Coon, J.J.; Amador-Noguez, D. Genome Wide Phosphoproteome Analysis of Zymomonas mobilis Under Anaerobic, Aerobic, and N2-Fixing Conditions. Front. Microbiol. 2019, 10, 1986. [CrossRef] [PubMed]

14. Wang, X.; He, Q.; Yang, Y.; Wang, J.; Haning, K.; Hu, Y.; Wu, B.; He, M.; Zhang, Y.; Bao, J.; et al. Advances and prospects in metabolic engineering of Zymomonas mobilis. Metab. Eng. 2018, 50, 57-73. [CrossRef] [PubMed]

15. Zhang, M.; Eddy, C.; Deanda, K.; Finkelstein, M.; Picataggio, S. Metabolic Engineering of a Pentose Metabolism Pathway in Ethanologenic Zymomonas mobilis. Science 1995, 267, 240. [CrossRef]

16. Yang, S.; Tschaplinski, T.J.; Engle, N.L.; Carroll, S.L.; Martin, S.L.; Davison, B.H.; Palumbo, A.V.; Rodriguez, M., Jr.; Brown, S.D. Transcriptomic and metabolomic profiling of Zymomonas mobilis during aerobic and anaerobic fermentations. BMC Genom. 2009, 10, 34. [CrossRef] [PubMed]

17. Kalnenieks, U.; Balodite, E.; Strähler, S.; Strazdina, I.; Rex, J.; Pentjuss, A.; Fuchino, K.; Bruheim, P.; Rutkis, R.; Pappas, K.M.; et al. Improvement of Acetaldehyde Production in Zymomonas mobilis by Engineering of Its Aerobic Metabolism. Front. Microbiol. 2019, 10, 2533. [CrossRef]

18. Julsing, M.K.; Kuhn, D.; Schmid, A.; Bühler, B. Resting cells of recombinant E. coli show high epoxidation yields on energy source and high sensitivity to product inhibition. Biotechnol. Bioeng. 2012, 109, 1109-1119. [CrossRef]

19. Kadisch, M.; Willrodt, C.; Hillen, M.; Bühler, B.; Schmid, A. Maximizing the stability of metabolic engineering-derived whole-cell biocatalysts. Biotechnol. J. 2017, 12, 1600170. [CrossRef]

20. Bevers, J.; Verachtert, H. Synthesis of higher alcohols in the genus Zymomonas. J. Inst. Brew. 1976, 82, 35-40. [CrossRef]

21. Fu, N.; Peiris, P.; Markham, J.; Bavor, J. A novel co-culture process with Zymomonas mobilis and Pichia stipitis for efficient ethanol production on glucose/xylose mixtures. Enzym. Microb. Technol. 2009, 45, 210-217. [CrossRef]

22. Wirawan, F.; Cheng, C.-L.; Kao, W.-C.; Lee, D.-J.; Chang, J.-S. Cellulosic ethanol production performance with SSF and SHF processes using immobilized Zymomonas mobilis. Appl. Energy 2012, 100, 19-26. [CrossRef]

23. Niu, X.; Wang, Z.; Li, Y.; Zhao, Z.; Liu, J.; Jiang, L.; Xu, H.; Li, Z. "Fish-in-Net", a Novel Method for Cell Immobilization of Zymomonas mobilis. PLoS ONE 2013, 8, e79569. [CrossRef] [PubMed]

24. Pentjuss, A.; Odzina, I.; Kostromins, A.; Fell, D.A.; Stalidzans, E.; Kalnenieks, U. Biotechnological potential of respiring Zymomonas mobilis: A stoichiometric analysis of its central metabolism. J. Biotechnol. 2013, 165, 1-10. [CrossRef] [PubMed]

25. Michalowski, A.; Siemann-Herzberg, M.; Takors, R. Escherichia coli HGT: Engineered for high glucose throughput even under slowly growing or resting conditions. Metab. Eng. 2017, 40, 93-103. [CrossRef] [PubMed]

26. Jang, C.; Chen, L.; Rabinowitz, J.D. Metabolomics and Isotope Tracing. Cell 2018, 173, 822-837. [CrossRef] 
27. Rutkis, R.; Kalnenieks, U.; Stalidzans, E.; Fell, D.A. Kinetic modelling of the Zymomonas mobilis Entner-Doudoroff pathway: Insights into control and functionality. Microbiology 2013, 159, 2674-2689. [CrossRef]

28. Hayashi, T.; Kato, T.; Watakabe, S.; Song, W.; Aikawa, S.; Furukawa, K. The respiratory chain provides salt stress tolerance by maintaining a low NADH/NAD+ ratio in Zymomonas mobilis. Microbiology 2015, 161, 2384-2394. [CrossRef]

29. Yang, S.; Mohagheghi, A.; Franden, M.A.; Chou, Y.-C.; Chen, X.; Dowe, N.; Himmel, M.E.; Zhang, M. Metabolic engineering of Zymomonas mobilis for 2,3-butanediol production from lignocellulosic biomass sugars. Biotechnol. Biofuels 2016, 9, 189. [CrossRef]

30. Wu, B.; Qin, H.; Yang, Y.; Duan, G.; Yang, S.; Xin, F.; Zhao, C.; Shao, H.; Wang, Y.; Zhu, Q.; et al. Engineered Zymomonas mobilis tolerant to acetic acid and low $\mathrm{pH}$ via multiplex atmospheric and room temperature plasma mutagenesis. Biotechnol. Biofuels 2019, 12, 10. [CrossRef]

31. Wang, J.-L.; Wu, B.; Qin, H.; You, Y.; Liu, S.; Shui, Z.-X.; Tan, F.-R.; Wang, Y.-W.; Zhu, Q.-L.; Li, Y.-B.; et al. Engineered Zymomonas mobilis for salt tolerance using EZ-Tn5-based transposon insertion mutagenesis system. Microb. Cell Factories 2016, 15, 101. [CrossRef]

32. Strazdina, I.; Kravale, Z.; Galinina, N.; Rutkis, R.; Poole, R.K.; Kalnenieks, U. Electron transport and oxidative stress in Zymomonas mobilis respiratory mutants. Arch. Microbiol. 2012, 194, 461-471. [CrossRef]

33. Kalnenieks, U.; Galinina, N.; Toma, M.M.; Pickford, J.L.; Rutkis, R.; Poole, R.K. Respiratory behaviour of a Zymomonas mobilis adhB::kan $\mathrm{r}$ mutant supports the hypothesis of two alcohol dehydrogenase isoenzymes catalysing opposite reactions. FEBS Lett. 2006, 580, 5084-5088. [CrossRef]

34. Galinina, N.; Lasa, Z.; Strazdina, I.; Rutkis, R.; Kalnenieks, U. Effect of ADH II deficiency on the intracellular redox homeostasis in Zymomonas mobilis. Sci. World J. 2012, 2012, 742610. [CrossRef] [PubMed]

35. Grube, M.; Bekers, M.; Upite, D.; Kaminska, E. IR-spectroscopic studies of Zymomonas mobilis and levan precipitate. Vib. Spectrosc. 2002, 28, 277-285. [CrossRef]

36. Low, K.S.; Rogers, P.L. The macromolecular composition and essential amino acid profiles of strains of Zymomonas mobilis. Appl. Microbiol. Biotechnol. 1984, 19, 75-78. [CrossRef]

37. Jöbses, I.M.L.; Egberts, G.T.C.; Luyben, K.C.A.M.; Roels, J.A. Fermentation kinetics of Zymomonas mobilis at high ethanol concentrations: Oscillations in continuous cultures. Biotechnol. Bioeng. 1986, 28, 868-877. [CrossRef]

38. Belenky, P.; Jonathan, D.Y.; Caroline, P.B.M.; Nadia, R.C.; Lobritz, M.A.; Ferrante, T.; Jain, S.; Korry, B.J.; Schwarz, E.G.; Walker, G.C.; et al. Bactericidal Antibiotics Induce Toxic Metabolic Perturbations that Lead to Cellular Damage. Cell Rep. 2015, 13, 968-980. [CrossRef] [PubMed]

39. Kalnenieks, U.; de Graaf, A.A.; Bringer-Meyer, S.; Sahm, H. Oxidative phosphorylation in Zymomonas mobilis. Arch. Microbiol. 1993, 160, 74-79. [CrossRef]

40. Kvitvang, H.F.N.; Kristiansen, K.A.; Bruheim, P. Assessment of capillary anion exchange ion chromatography tandem mass spectrometry for the quantitative profiling of the phosphometabolome and organic acids in biological extracts. J. Chromatogr. A 2014, 1370, 70-79. [CrossRef]

41. Stafsnes, M.H.; Røst, L.M.; Bruheim, P. Improved phosphometabolome profiling applying isotope dilution strategy and capillary ion chromatography-tandem mass spectrometry. J. Chromatogr. B 2018, 1083, 278-283. [CrossRef]

42. Cohen, S.A.; Strydom, D.J. Amino acid analysis utilizing phenylisothiocyanate derivatives. Anal. Biochem. 1988, 174, 1-16. [CrossRef]

43. Tan, B.; Lu, Z.; Dong, S.; Zhao, G.; Kuo, M.-S. Derivatization of the tricarboxylic acid intermediates with O-benzylhydroxylamine for liquid chromatography-tandem mass spectrometry detection. Anal. Biochem. 2014, 465, 134-147. [CrossRef] [PubMed]

(C) 2020 by the authors. Licensee MDPI, Basel, Switzerland. This article is an open access article distributed under the terms and conditions of the Creative Commons Attribution (CC BY) license (http://creativecommons.org/licenses/by/4.0/). 